\title{
Antigenic characterisation of lyssaviruses in South Africa
}

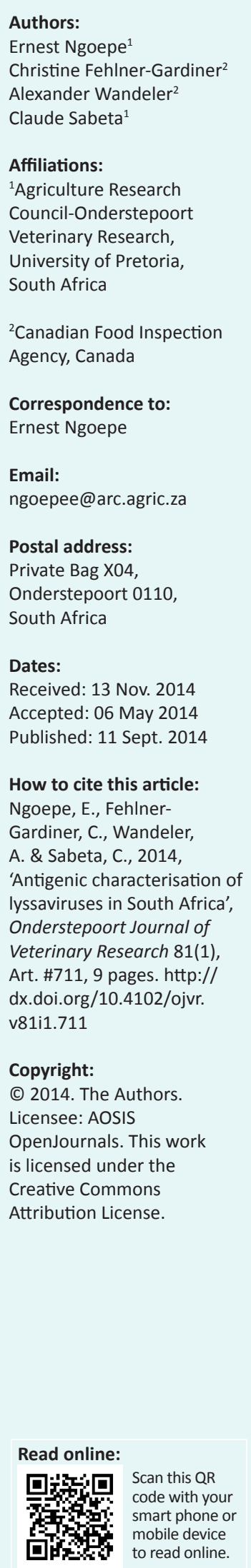

There are at least six Lyssavirus species that have been isolated in Africa, which include classical rabies virus, Lagos bat virus, Mokola virus, Duvenhage virus, Shimoni bat virus and Ikoma lyssavirus. In this retrospective study, an analysis of the antigenic reactivity patterns of lyssaviruses in South Africa against a panel of 15 anti-nucleoprotein monoclonal antibodies was undertaken. A total of 624 brain specimens, collected between 2005 and 2009, confirmed as containing lyssavirus antigen by direct fluorescent antibody test, were subjected to antigenic differentiation. The lyssaviruses were differentiated into two species, namely rabies virus (99.5\%) and Mokola virus (0.5\%). Furthermore, rabies virus was further delineated into two common rabies biotypes in South Africa: canid and mongoose. Initially, it was found that the canid rabies biotype had two reactivity patterns; differential staining was observed with just one monoclonal antibody. This difference was likely to have been an artefact related to sample quality, as passage in cell culture restored staining. Mongoose rabies viruses were more heterogeneous, with seven antigenic reactivity patterns detected. Although Mokola viruses were identified in this study, prevalence and reservoir host species are yet to be established. These data demonstrate the usefulness of monoclonal antibody typing panels in lyssavirus surveillance with reference to emergence of new species or spread of rabies biotypes to new geographic zones.

\section{Introduction}

Rabies is a viral zoonotic disease caused by lyssaviruses that are capable of infecting all mammalian species. These viruses belong to the Lyssavirus genus of the Rhabdoviridae family. The Lyssavirus genus consists of 14 recognised viral species based on serological assays, genetic distances of the nucleoprotein gene, topology and consistency of the phylogenetic trees, antigenic patterns in reaction with anti-nucleocapsid monoclonal antibodies and/or other additional characters such as ecological properties, host and geographic range and pathological features (Dietzgen et al. 2011; ICTV 2014). These includes classical rabies virus (RABV) and the other viral species are referred to as rabies-related viruses. Of the 14 species, only six have been identified and isolated in Africa to date, namely: RABV, Lagos bat virus (LBV), Mokola virus (MOKV), Duvenhage virus (DUVV), Shimoni bat virus (SHIBV) and Ikoma lyssavirus (IKOV). In addition, Lleida bat lyssavirus was recently proposed as a putative species of the Lyssavirus genus (Freuling et al. 2011; Marston et al. 2012). Within the classical rabies virus two common variants have been identified in southern Africa: the canid rabies and mongoose rabies biotypes (King, Meredith \& Thomson 1993; Nel et al. 2005; Von Teichman et al. 1995). Rabies in mongooses was first identified in southern Africa in the 1800s (Snyman 1940; Swanepoel 2004). In contrast, rabies in dogs appears to have spread into southern Africa via the north-west from Angola in the 1940s, and by the 1950s dog rabies had entered Zimbabwe and South Africa, where it became established in various canid host species in subsequent years (Nadin-Davis \& Bingham 2004). In South Africa, rabies still remains a significant public and veterinary health threat, as the disease is well maintained by various host species.

Genetic typing by nucleotide sequence analysis and antigenic typing using discriminatory monoclonal antibody $(\mathrm{mAb})$ panels in an indirect immunofluorescence assay (IFA) can be used to differentiate Lyssavirus species, as well as variants within the species (Favoretto et al. 2002; Favoretto et al. 2006; Smith 2002). The discriminatory capability of IFA is generally determined by the number of mAbs used in a panel (Nadin-Davis et al. 2010; Smith 2002). Antigenic typing panels generally depend on mAbs specific for the nucleoprotein $(\mathrm{N})$ and phosphoprotein $(\mathrm{P})$; glycoprotein $(\mathrm{G}) \mathrm{mAbs}$ can also be used. In addition, specific mAb panels have also been generated and used to map antigenic sites on these proteins to characterise lyssaviruses, and also to distinguish RABV variants persisting in geographically restricted host reservoirs (NadinDavis et al. 2010; Rupprecht et al. 1991; Smith \& King 1996). Lyssavirus typing with mAbs provides a rapid and inexpensive screening method for large-scale surveillance of both new lyssaviruses (Gould et al. 1998) and common or emerging variants of the rabies virus (Nadin- 
Davis et al. 2000). This technology was used to differentiate between street virus and the rabies vaccine strain during the oral vaccination campaigns against fox rabies in Western Europe and in Ontario, Canada (Fehlner-Gardiner et al. 2008; Schneider et al. 1988). In previous studies, a panel of 80 anti-nucleoprotein $\mathrm{mAbs}$ was used to differentiate rabies viruses from Namibia and South Africa (King et al. 1993). It was shown that canid rabies viruses conformed to a single reactivity pattern, whereas mongoose rabies viruses had several variations in their reactivity patterns (King et al. 1993). This retrospective study describes the mAb typing of lyssavirus isolates collected in South Africa from different animal species between 2005 and 2009 is reported on.

\section{Materials and methods Brain specimens}

The specimens were routinely submitted to the Agricultural Research Council-Ondestepoort Veterinary Institute (ARC-OVI) for rabies diagnosis from various provinces of South Africa except the Western Cape and KwazuluNatal (KZN), which submit samples to Allerton Veterinary Laboratory, KZN and Western Cape provincial veterinary laboratory (Figure 1). All the samples were confirmed to be positive for lyssavirus antigen by direct fluorescent antibody test (dFAT) using fluorescently labelled goat antiserum raised against purified RABV and MOKV ribonucleoproteins (Dean, Abelseth \& Atanasiu 1996). A total of 624 brain specimens, collected between 2005 and 2009, from different animal species were analysed by mAb-IFA.

\section{Antigenic analysis by immunofluorescence assay}

A panel of 16 murine mAbs discriminating between different southern African Lyssavirus species and antigenic variants were chosen from the $\mathrm{mAb}$ collection of the Centre of Expertise for Rabies of the Canadian Food Inspection Agency (Ottawa, Canada). The panel included an anti-human adenovirus type- $5 \mathrm{mAb}$ (1C5) as negative control and 15 antirabies virus nucleoprotein $\mathrm{mAbs}$, which included a positive control (38HF2) that had reacted with all tested lyssaviruses. The reactivity patterns for the canid and mongoose rabies virus biotypes, MOKV, LBV and DUVV established during the selection of mAbs for this panel are shown in Table 1.

Brain smears were prepared on Teflon-coated $5 \mathrm{~mm}$ well slides and fixed in cold $80 \%$ acetone, ACS grade (Merck Chemicals, Germany) for at least $20 \mathrm{~min}$. To each well on the slide, $80 \mu \mathrm{L}$ of $\mathrm{mAb}$ (in hybridoma supernatant) was added and incubated at $37^{\circ} \mathrm{C}$ for $50 \mathrm{~min}-60 \mathrm{~min}$. The slides were removed from the incubator and rinsed twice with Tris buffer $(7.2 \mathrm{pH}-7.4 \mathrm{pH})$ for $5 \mathrm{~min}-10 \mathrm{~min}$, followed by three rinses with phosphate buffered saline (PBS) $(7.2 \mathrm{pH}-7.4 \mathrm{pH})$ for $8 \mathrm{~min}-10 \mathrm{~min}$ each. After air-drying, $80 \mu \mathrm{L}$ of fluorescein isothiocyanate-conjugated goat antimouse IgG antibody (Sigma-Aldrich, USA) was added to each well and the slides were incubated at $37{ }^{\circ} \mathrm{C}$ for $40 \mathrm{~min}-60 \mathrm{~min}$. The slides were rinsed with Tris buffer for $5 \mathrm{~min}$ - $10 \mathrm{~min}$ and counterstained with Evans Blue $(0.5 \%)$ for $40 \mathrm{~s}$. The slides were dried by blotting them on a paper towel, then they were cover-slipped using aqueous mounting medium (50\% PBS, $7.2 \mathrm{pH}-7.4 \mathrm{pH}$ and 50\% glycerol) and examined using ultraviolet fluorescence microscopy (Carl Zeiss, Germany). The IFA reactivity for each $\mathrm{mAb}$ was recorded as positive $(+)$ or negative (-) to generate the overall staining pattern for each isolate. The test was repeated only when non-specific results with either negative or positive controls (1C5 and 38HF2) were obtained.

\section{Viruses included in the analysis}

Further phylogenetic analyses and comparison with phylogroups determined from previous studies (Nel et al. 2005; Van Zyl, Markotter \& Nel 2010) were carried out on a panel of 21 representative isolates selected from the seven mongoose biotype groups detected with antigenic typing and from six isolates selected from the canid biotype groups. The year of isolation, host species and geographical origin of

TABLE 1: Typical reactivity patterns of African lyssaviruses against a panel of 16 monoclonal antibodies.

\begin{tabular}{|c|c|c|c|c|c|c|}
\hline $\begin{array}{l}\text { Monoclonal antibody } \\
\text { number }\end{array}$ & $\begin{array}{l}\text { Monoclonal } \\
\text { antibody }\end{array}$ & $\begin{array}{l}\text { Canid rabies } \\
\text { biotype }\end{array}$ & $\begin{array}{l}\text { Mongoose rabies } \\
\text { biotype }\end{array}$ & Lagos bat virus & Mokola virus & Duvenhage virus \\
\hline 1 & $1 \mathrm{C5}$ & - & - & - & - & - \\
\hline 2 & $26 \mathrm{AB} 7$ & + & variable & - & - & - \\
\hline 3 & 26BE2 & + & variable & - & - & - \\
\hline 4 & 32GD12 & variable & variable & - & - & - \\
\hline 5 & $38 \mathrm{HF} 2$ & + & + & + & + & + \\
\hline 6 & M612 & - & - & + & - & - \\
\hline 7 & M837 & - & - & - & - & + \\
\hline 8 & M850 & - & variable & - & - & + \\
\hline 9 & M853 & + & - & - & - & + \\
\hline 10 & M1001 & - & - & - & + & - \\
\hline 11 & M1335 & - & variable & - & variable & - \\
\hline 12 & M1386 & - & + & - & - & - \\
\hline 13 & M1400 & - & variable & - & - & - \\
\hline 14 & M1407 & + & variable & - & - & - \\
\hline 15 & M1412 & + & variable & - & - & - \\
\hline 16 & M1494 & - & variable & - & - & + \\
\hline
\end{tabular}

Note: -, no reactivity; +, reactivity observed; variable, some isolates within the species or biotype react with the mAb and others do not react. 
TABLE 2: Representative mongoose rabies variants from each antigenic group that were included in phylogenetic analyses.

\begin{tabular}{|c|c|c|c|c|c|c|c|c|}
\hline $\begin{array}{l}\text { Virus } \\
\text { number }\end{array}$ & $\begin{array}{l}\text { Laboratory } \\
\text { number }\end{array}$ & Species of origin & Locality of origin & Year of isolation & $\begin{array}{l}\text { Antigenic } \\
\text { group }\end{array}$ & Target gene & $\begin{array}{l}\text { Accession } \\
\text { number }\end{array}$ & Phylogenetic cluster \\
\hline 1 & $418 / 06$ & Cynictis penicillata & Hoopstad & 2006 & $A$ & JN162088 (G-L) & JQ692993 (N) & IV \\
\hline 2 & $257 / 05$ & Cynictis penicillata & Fouriesburg & 2005 & $A$ & JN162084 (G-L) & JQ692995 (N) & IV \\
\hline 3 & $456 / 06$ & Felis lybica & Bethlehem & 2006 & B & JN162089 (G-L) & JQ692988 (N) & III \\
\hline 4 & $116 / 08$ & Cynictis penicillata & Belfast & 2008 & B & JN162083 (G-L) & JQ692983 (N) & ॥ \\
\hline 5 & $18 / 06$ & Felis lybica & Bethlehem & 2006 & B & JN162078 (G-L) & JQ692985 (N) & III \\
\hline 6 & $57 / 06$ & Cynictis penicillata & Ermelo & 2006 & C & JN162090 (G-L) & JQ692990 (N) & III \\
\hline 7 & $06 / 06$ & Ovis aries & De Aar & 2006 & C & JQ692997 (G-L) & JQ692981 (N) & IV \\
\hline 8 & $200 / 06$ & Galerella pulverulenta & Hoopstad & 2006 & $\mathrm{D}$ & JQ692999 (G-L) & JQ692986 (N) & IV \\
\hline 9 & $131 / 08$ & Galerella sanguinea & Potchefstroom & 2008 & $\mathrm{D}$ & JN162082 (G-L) & JQ692984 (N) & III \\
\hline 10 & $50 / 06$ & Bos taurus & Middelburg & 2006 & $\mathrm{D}$ & JN162079 (G-L) & JQ692989 (N) & ॥ \\
\hline 11 & $696 / 06$ & Cynictis penicillata & Kroonstad & 2006 & E & JN162080 (G-L) & JQ692994 (N) & III \\
\hline 12 & $13 / 07$ & Felis lybica & Kroonstad & 2007 & E & JN162086 (G-L) & JQ692996 (N) & III \\
\hline 13 & $06 / 07$ & Bos taurus & Kroonstad & 2007 & E & JQ692998 (G-L) & JQ692982 (N) & III \\
\hline 16 & $265 / 06$ & Cynictis penicillata & Bethlehem & 2006 & G & JN162081 (G-L) & JQ692992 (N) & III \\
\hline 17 & $28 / 06$ & Bos taurus & Heilbron & 2006 & C & JX088733 (G-L) & JX088728 (N) & III \\
\hline 18 & $235 / 07$ & Bos taurus & Frankfort & 2007 & $\mathrm{~F}$ & JX088734 (G-L) & JX088729 (N) & III \\
\hline 19 & $397 / 07$ & Bos taurus & Leeudoringstad & 2007 & $\mathrm{~F}$ & JX088735 (G-L) & JX088730 (N) & III \\
\hline 20 & $416 / 07$ & Galerella sanguinea & Bloemfontein & 2007 & G & JX088736 (G-L) & JX088731 (N) & IV \\
\hline 21 & $584 / 06$ & Felis lybica & Smithfield & 2006 & A & JX088737 (G-L) & JX088732 (N) & IV \\
\hline
\end{tabular}

Note: The accession numbers of the targeted genes are also shown, whereby, G-L denotes G-L intergenic region and N denotes full nucleoprotein nucleotide sequences.

the mongoose biotype isolates are shown in Table 2.

\section{Viral RNA extraction and reverse transcription polymerase chain reaction}

Total viral RNA was extracted from original brain material using Trizol ${ }^{\circledR}$ reagent (Sigma-Aldrich, USA) according to the manufacturer's instructions. For the cDNA synthesis of the G-L intergenic region and nucleoprotein genes, $5 \mu \mathrm{L}$ of total RNA (approximately $2 \mu \mathrm{g}$ ) and $20 \mathrm{pmol}$ of the positive sense primers $(2 \mu \mathrm{L}), 001$ lys (N-gene) and $\mathrm{G}(+)$ (G-L intergenic region) (Table 3) were denatured at $65{ }^{\circ} \mathrm{C}$ for $5 \mathrm{~min}$. The reaction mixtures were immediately cooled on ice and RNA was reverse transcribed at $42{ }^{\circ} \mathrm{C}$ for $60 \mathrm{~min}$ in a $20 \mu \mathrm{L}$ reaction mixture containing 200 U Superscript III reverse transcriptase (Invitrogen), $4 \mu \mathrm{L}$ of reaction buffer, $10 \mathrm{mM}$ deoxynucleotide triphosphates (dNTPs) and $40 \mathrm{U}$ of RNase inhibitor (Promega, USA). The polymerase chain reactions (PCRs) were performed in a total volume of $50 \mu \mathrm{L}$ containing $1 \mathrm{X}$ PCR reaction buffer, $1.5 \mathrm{mM} \mathrm{MgCl}_{2}, 250 \mu \mathrm{M}$ of each dNTP, $5 \mu \mathrm{L}$ of cDNA, $1.25 \mathrm{U}$ of Taq DNA polymerase (Applied Biosystem, USA) and 40 pmol of each of the primers (G [+] and L [-], 001lys and 304) (Table 3). The amplification reactions were performed in a Geneamp 2400 thermocycler with an initial denaturation of $94{ }^{\circ} \mathrm{C}$ for $2 \mathrm{~min}$, followed by 40 cycles ( 25 cycles) of denaturation at $94{ }^{\circ} \mathrm{C}$, primer annealing at $37{ }^{\circ} \mathrm{C}$ for $30 \mathrm{~s}$ ( $42{ }^{\circ} \mathrm{C}$ for $90 \mathrm{~s}$ ) and primer extension at $72{ }^{\circ} \mathrm{C}$ for $90 \mathrm{~s}$ followed by a final extension at $72{ }^{\circ} \mathrm{C}$ for $7 \mathrm{~min}$ (values in parenthesis indicate conditions for $\mathrm{G}$ - $\mathrm{L}$ intergenic region). The amplicons were subsequently analysed by ethidium bromide-stained agarose gel (1\%) electrophoresis.

\section{DNA purification, nucleotide sequencing and phylogenetic analysis}

The PCR products were purified using the DNA purification kit according to the manufacturer's instructions (Promega, USA). The purified products were sequenced in both directions
TABLE 3: Oligonucleotide primers used in the study showing annealing positions and nucleotide sequences.

\begin{tabular}{|c|c|c|}
\hline Oligonucleotide & Nucleotide sequence 5'-3' & Reference \\
\hline 001lys -70 to $-57(+)$ & ACGCTTAACGAMAAA & Markotter et al. 2006 \\
\hline $304_{1514-1533}(-)$ & TTGACAAAGATCTTGCTCAT & Markotter et al. 2006 \\
\hline $\mathrm{G}_{4665-4687}(+)$ & GACTTGGGTCTCCCGAACTGGGG & Sacramento et al. 1991 \\
\hline $\mathrm{L}_{5543-5520}(-)$ & CAAAGGAGAGTTGAGATTGTAGTC & Sacramento et al. 1991 \\
\hline
\end{tabular}

using both primer sets used in the reverse transcription polymerase chain reaction (RT-PCR) step together with the sequencing kit according to the manufacturer's instructions (Applied Biosystems, USA). The sequencing products were electrophoresed on an ABI 377 automated sequencer (Applied Biosystems) and the consensus sequences of 1353 nucleotides (nt) of the N gene and 592 nt (G-L intergenic region) were obtained by using MEGA 3.1 sequence editor (Kumar, Tamura \& Nei 2004). The phylogenetic trees were constructed using the neighbour joining (NJ) method in Clustal X (Saitou \& Nei 1987). Two sets of 18 full-length nucleoprotein and partial G-L intergenic region nucleotide sequences representing previous mongoose RABV phylogroups from southern Africa were retrieved from Genbank and included for phylogenetic analysis. The branching order of the trees was statistically evaluated by 1000 bootstrap replicates; values of more than 700 (70\%) were considered to be statistically significant (Hills \& Bull 1993).

\section{Results}

Of the 624 samples included for analysis, 99.5\% (621) had staining patterns consistent with those established for RABV, and $0.5 \%$ (3) had patterns consistent with that of MOKV. The RABV isolates were identified from various animal species in all provinces of South Africa included in 
the present study. Mokola virus isolates were identified in the provinces of Mpumalanga $(n=1)$ from a domestic dog, and Eastern Cape $(n=2)$ from domestic cats (Figure 1$)$. The RABV isolates were further differentiated into the canid $(438 / 621,70.5 \%)$ and mongoose $(183 / 621,29.5 \%)$ rabies biotypes. The canid RABV biotype was primarily confirmed in rabies cases obtained from domestic dogs $(216 / 438,49 \%)$, black-backed jackals (Canis mesomelas) $(29 / 438,7 \%)$ and bat-eared foxes (Otocyon megalotis) (29/438, 7\%), whereas the mongoose RABV biotype was recovered mainly in Herpestidae species, especially the yellow mongoose $(82 / 183,45 \%)$. Moreover, there were two mongoose rabies biotype cases detected in Limpopo province from a blackbacked jackal and a domestic dog (Figure 1).

The canid RABV biotype isolates fell into two categories, with differences observed only with mAb 32GD12 (Table 4). The majority of the canid viruses (403/438, 92\%) were stained by this mAb (reactivity pattern I). Although viruses that conformed to canid biotype reactivity pattern II were less common, they exhibited similar geographic
TABLE 4: Indirect immunofluorescence assay reactivity patterns of canid rabies viruses obtained from South Africa.

\begin{tabular}{llll}
\hline mAb number & mAb & Reactivity pattern I & Reactivity pattern II \\
\hline 1 & $1 C 5$ & - & - \\
2 & $26 \mathrm{AB7}$ & + & + \\
3 & $26 \mathrm{BE} 2$ & + & + \\
4 & $32 \mathrm{GD} 12 \dagger$ & + & - \\
5 & $38 \mathrm{HF2}$ & + & + \\
6 & M612 & - & - \\
7 & M837 & - & - \\
8 & M850 & - & - \\
9 & M853 & + & + \\
10 & M1001 & - & - \\
11 & M1335 & - & - \\
12 & M1386 & - & - \\
13 & M1400 & - & - \\
14 & M1407 & + & + \\
15 & M1412 & + & + \\
16 & M1494 & - & - \\
\hline Total number of & - & 403 (92\%) & $\mathbf{3 5 \% )}$ \\
cases & & & \\
\hline
\end{tabular}

$\mathrm{mAb}$, monoclonal antibody; - , no reactivity; +, reactivity observed.

$\downarrow$ This is the only mAB (32GD12) that differentiates between reactivity patterns I and II of canid rabies viruses.

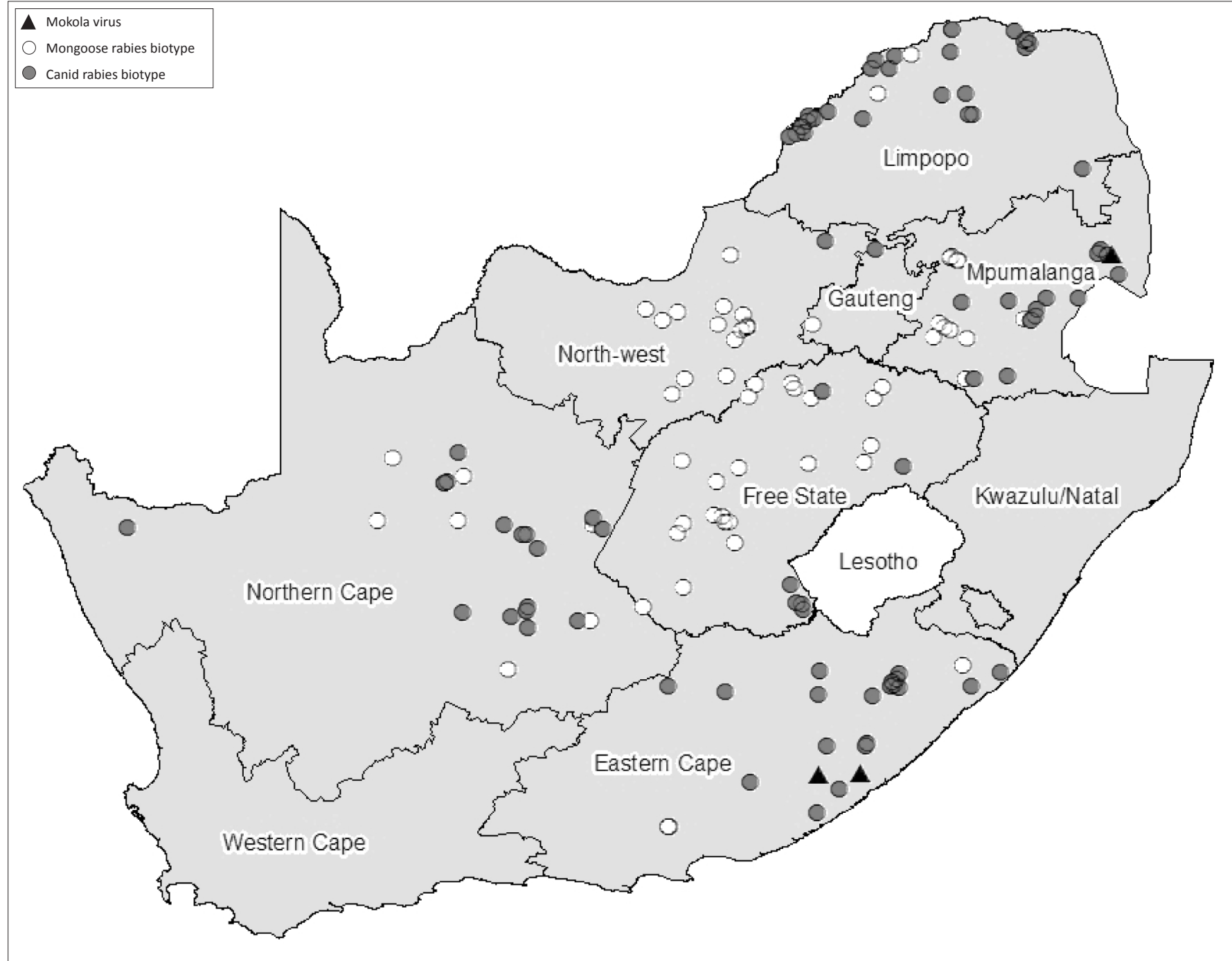

Source: Authors' own creation

FIGURE 1: The geographical distribution of lyssavirus variants identified and received in South Africa between 2005 and 2009 at the Agricultural Research CouncilOnderstepoort Veterinary Institute. 
TABLE 5: Indirect immunofluorescence assay reactivity patterns obtained for mongoose rabies viruses.

\begin{tabular}{|c|c|c|c|c|c|c|c|}
\hline \multirow[t]{2}{*}{$\mathrm{mAb}$} & \multicolumn{7}{|c|}{ Groups } \\
\hline & A & B & C & D & $E$ & $\mathbf{F}$ & $\mathbf{G}$ \\
\hline $1 \mathrm{C} 5$ & - & - & - & - & - & - & - \\
\hline $26 A B 7$ & + & + & + & + & + & + & + \\
\hline 32GD12 & - & - & - & - & - & + & - \\
\hline $38 \mathrm{HF} 2$ & + & + & + & + & + & + & + \\
\hline M612 & - & - & - & - & - & - & - \\
\hline M837 & - & - & - & - & - & - & - \\
\hline M850 & + & - & - & - & - & - & + \\
\hline M853 & - & - & - & - & - & - & - \\
\hline M1001 & - & - & - & - & - & - & - \\
\hline M1335 & - & + & - & - & + & + & + \\
\hline M1386 & + & + & + & + & + & + & + \\
\hline M1400 & + & + & - & + & - & + & + \\
\hline M1407 & + & + & + & + & + & + & + \\
\hline M1412 & + & + & + & + & + & + & + \\
\hline
\end{tabular}

mAb, monoclonal antibody.

TABLE 6: The distribution of mongoose rabies virus variant antigenic reactivity patterns by host species.

\begin{tabular}{|c|c|c|c|c|c|c|c|c|}
\hline \multirow[t]{2}{*}{ Scientific name } & \multirow[t]{2}{*}{ Common name } & \multicolumn{7}{|c|}{ Antigenic group } \\
\hline & & A & B & $\mathrm{C}$ & D & $E$ & $\mathbf{F}$ & G \\
\hline Cynictis penicillata & Yellow mongoose & 12 & 20 & 12 & 16 & 10 & 4 & 8 \\
\hline Canis familiaris & Domestic dog & 2 & 3 & - & 3 & 2 & 2 & - \\
\hline Canis mesomelas & Black backed jackal & 1 & - & - & 1 & - & - & 1 \\
\hline Felis lybica & African wildcat & 2 & 9 & 7 & 4 & 2 & 3 & - \\
\hline Bovine & Cattle & 5 & 6 & - & 5 & 3 & 4 & 3 \\
\hline Genetta genetta & Genet & - & 1 & - & 1 & - & - & - \\
\hline Xerus inauris & Ground squirrel & - & - & - & 1 & - & - & - \\
\hline Suricata suricatta & Meerkat & 1 & 2 & 1 & 2 & - & 2 & - \\
\hline Galerella pulverulenta & Grey mongoose & - & - & 3 & 4 & - & 3 & - \\
\hline Ovis aries & Sheep & - & - & - & 1 & - & - & - \\
\hline Galerella sanguinea & Slender mongoose & 2 & - & - & 3 & - & - & 2 \\
\hline Sylvicapra grimmia & Duiker & - & 1 & - & - & - & - & - \\
\hline Atilax paludinasus & Water mongoose & - & - & - & - & - & - & 1 \\
\hline Proteles cristatus & Aardwolf & 1 & - & - & - & - & - & - \\
\hline Total & - & 26 & 42 & 24 & 41 & 17 & 18 & 15 \\
\hline
\end{tabular}

distribution to viruses that conformed to canid biotype reactivity pattern I (Figure 1). Among the mongoose RABV biotypes, seven antigenic reactivity patterns (A-G) were detected (Table 5) and these viruses were recovered from a wide range of different animal species (Table 6). Mongoose rabies biotype viruses that conformed to group B and D staining patterns were most common (Table 5). However, the antigenic reactivity patterns do not appear to have any species-specific association with the different hosts (Table 6).

The PCR amplicons generated from the selected isolates were of the expected size of approximately $850 \mathrm{bp}$ (G-L region) and $1680 \mathrm{bp}$ (N-gene). Sequencing yielded about 740 bases (G-L region) and 1400 bases ( $\mathrm{N}$-gene) of sequence on average, which were trimmed to a consensus of 592 and 1353 nucleotides (nt) for phylogenetic analysis (data not shown). Representative canid RABV isolates conforming to both reactivity patterns ( $n=3$ for each group) had $98 \%$ nucleotide sequence identity in the nucleoprotein-encoding region (data not shown).

For the mongoose biotype, phylogenetic analysis of representative isolates from each group $(n=21)$ revealed trees with similar topologies when analysing either the partial G-L intergenic region or the full-length nucleoprotein nucleotide sequences (Figure 2a and Figure 2b). Isolates corresponding to staining pattern $\mathrm{A}(n=3)$ all clustered within the previously described phylogroup IV, whereas those with staining pattern $\mathrm{E}(n=3)$ and $\mathrm{F}(n=3)$ clustered within phylogroup III. These isolates also clustered geographically with other isolates that fell within phylogroups III and IV (Figure 2). In contrast, the isolates corresponding to the other staining patterns (B, C, D, F and G) did not group together under a single phylogroup, and did not exhibit geographical clustering, as observed for isolates with staining patterns A, $\mathrm{E}$ and $\mathrm{F}$. Thus, two of the three isolates with staining patterns B, C and G clustered with phylogroup III, whilst the third isolate examined fell within phylogroup II and IV. The three viruses with staining pattern D fell within phylogroups II, III and IV. Whilst the isolates from staining pattern groups B, C, D, and G did not cluster geographically, they did map to similar geographic areas with other isolates belonging to the same phylogroups (Figure 2).

\section{Discussion}

The geographical distribution of the rabies cases detected 


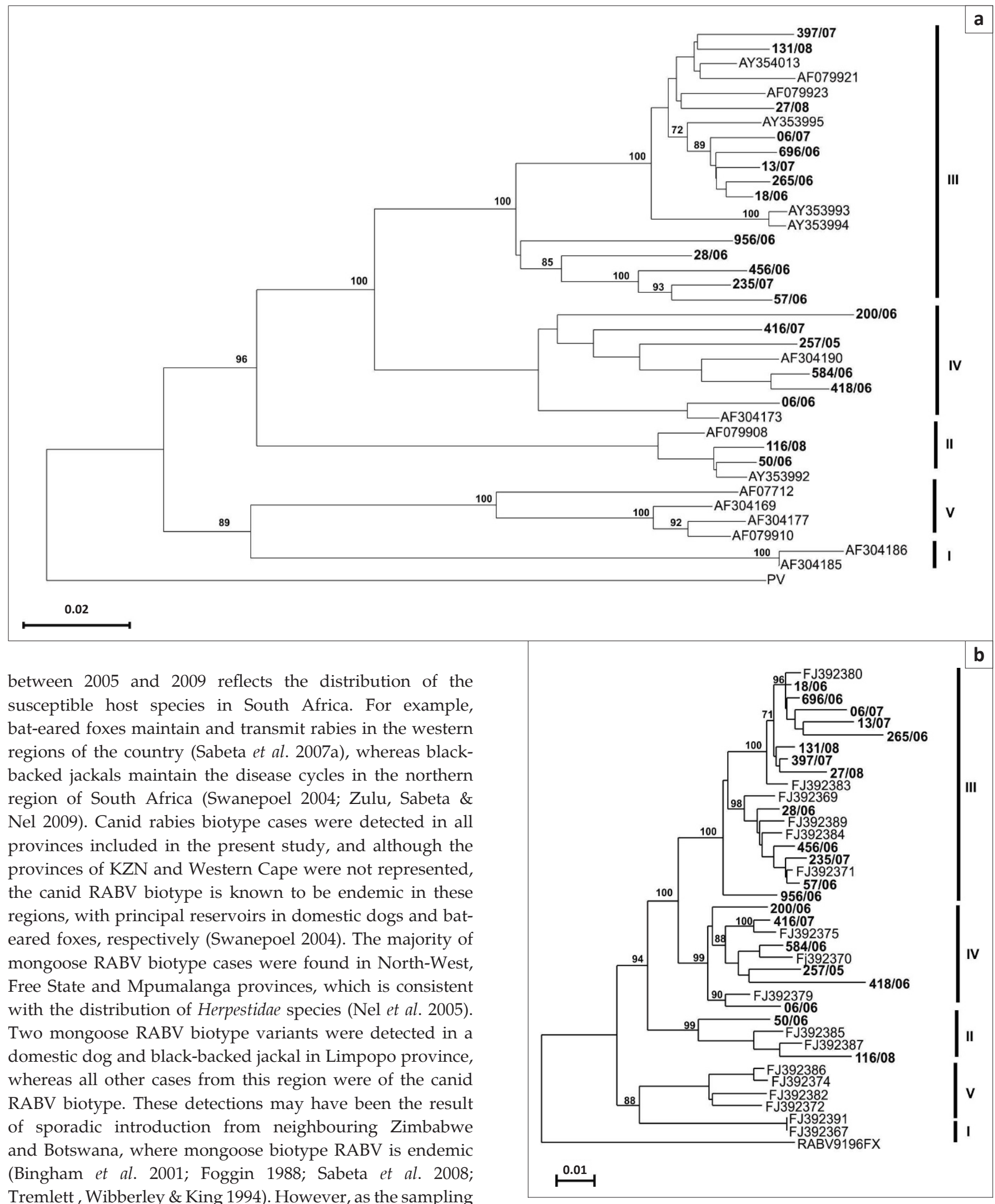
Tremlett , Wibberley \& King 1994). However, as the sampling method was only passive, relying on the state authorities to submit animal rabies suspected cases to the laboratory, it is possible that the mongoose RABV biotype is also established in this region of South Africa, but its prevalence

Source: Authors' own creation

Note: Bootstrap values are indicated at the branch nodes and branch lengths are drawn to scale. Both RABV9196FX and PV were used as out groups.

FIGURE 2: The neighbour-joining tree based on 1353 nucleotide sequences of nucleoprotein (a) and 592 nucleotide sequences of the G-L intergenic region (b) of the 21 mongoose rabies viruses selected from antigenic groups. 
underestimated. Spill-over of the mongoose rabies biotype from the host species is common; for example, mongoose RABVs were recovered from domestic dogs, sheep and cattle in the present study. In contrast, spillover of the canid RABV biotype into non-canid wildlife species is rarely observed (Von Teichman et al. 1995). Understanding the movement of RABV biotype and particularly spillover of wildlife variants into domestic animals and vice versa is a key aspect in the rabies control in the region.

The mAb panel used in this study was originally selected to differentiate amongst canid and mongoose biotypes of the rabies virus, as well as the non-rabies Lyssavirus species of MOKV, LBV and DUVV circulating in the region (Bingham et al. 2001). Several different staining patterns were observed for the rabies viruses in the present study, notably two for the canid biotype and seven for the mongoose biotype. A similar variation in $\mathrm{mAb}$ reactivity patterns was observed amongst the mongoose viruses in previous studies (King et al. 1993; Tremlett et al. 1994). In contrast, a single antigenic reactivity pattern of the canid RABV biotype was previously observed in isolates from South Africa and Namibia (King et al. 1993). In previous phylogenetic studies, whilst seven canid RABV biotype variants or clusters were observed in the Northern provinces of South Africa, they conformed to a single antigenic typing pattern (Agricultural Research CouncilOnderstepoort Veterinary Institute 2007; Zulu 2007). Similar observations were made in a study from Botswana, where antigenic typing could not differentiate smaller clades or subgroupings established by phylogenetic analyses (Johnson et al. 2004). It is unlikely that the detection of two reactivity patterns for the canid RABV biotype in the present study is due to a superior performance of the current $\mathrm{mAb}$ panel distinguishing between two variants that have long co-existed in the region. However, if this scenario were the case, observation of some geographic segregation of the variants would be expected, and it was not. Given that the observed canid RABV reactivity patterns differed by only one mAb (32GD12), it is more likely that the epitope recognised by mAb 32GD12 is unstable and the observed staining variability was an artefact of the quality of the tissue that was sampled. When the five canid rabies viruses that had antigenic reactivity pattern II were grown in cell culture, reactivity with mAb 32GD12 was restored, suggesting that the epitope recognised by this $\mathrm{mAb}$ is indeed unstable (data not shown). This is further supported by the observation that comparison of the $\mathrm{N}$-gene nucleotide sequence of multiple isolates conforming to each reactivity pattern indicated that they were $98 \%$ identical, and predicted amino acid sequences of $\mathrm{N}$ protein revealed no sequence motif that could explain the specific binding of mAb 32GD12 to reactivity pattern indicated that they I isolates alone (data not shown). A phylogenetic study of canid biotype viruses from Free State province and surrounding areas, collected between 1995 and 2007, showed similar high nucleotide sequence identity (Ngoepe, Sabeta \& Nel 2009).

Molecular phylogeny studies using both G-L intergenic region and full-length nucleoprotein nucleotide sequences showed that the mongoose RABV biotype from southern Africa (Zimbabwe and South Africa) could be differentiated into five main clades, which are consistent with their geographic localities (Nel et. al., 2005; Van Zyl et. al. 2010). In contrast, in the present study, mAb typing revealed seven antigenic reactivity patterns within the mongoose RABV biotype. However, the selected isolates from each antigenic group clustered within just three of the five clades previously determined ( $\mathrm{Nel}$ et al. 2005; Van Zyl et al. 2010). Concordant results were obtained whether the G-L intergenic region or the nucleoprotein nucleotide sequence was used for phylogenetic analysis. A high degree of diversity in mongoose rabies isolates examined with $\mathrm{mAbs}$ using a different $\mathrm{mAb}$ panel was also observed in studies in Botswana (Tremlett et al. 1994). The heterogeneous reactivity patterns observed within the mongoose RABV variant have been interpreted as supporting the hypothesis that the mongoose RABV variant has existed in this region for a longer period than the canid RABV variant and has therefore adapted well into the host species of this specific geographic locality (Nadin-Davis \& Bingham 2004). Molecular clock analyses have supported this hypothesis and estimate the age of the mongoose RABV to be in the range of 200 years, consistent with anecdotal evidence from the historical record (Van Zyl et al. 2010). The heterogeneity in $\mathrm{mAb}$ reactivity patterns observed in the present study is somewhat puzzling; however, not all of the different reaction patterns are associated with a given host species or geographic origin. In addition, only the antigenic types A, E and F are found on distinct branches of the sequence-based phylogenetic tree. Antigenic types B, $C, D$, and $G$ are scattered over three of the five branches of the tree, with the three group D isolates falling into three different clades. It might well be that these are artefacts related to sample quality, as observed with the canid biotypes. These observations highlight the limitation of using the current $\mathrm{mAb}$ panel for higher resolution studies of RABV sub-variants.

The retrospective analysis of the present study confirms not only the presence of the two RABV biotypes but also the rare MOKV in South Africa. The true prevalence and the host species of MOKV are yet to be established. In southern Africa, MOKV has only been isolated from domestic cats, with one exception from a dog (Sabeta et al. 2007b). Since domestic cats are unknown to be a reservoir species for any lyssavirus, it is likely that they exist in close association with the true MOKV reservoir and are incidental hosts for this Lyssavirus species. The ability to identify MOKV quickly using mAbs is of great importance since the current vaccines do not protect against MOKV infections (Badrane et al. 2001; Von Teichman et al. 1998).

\section{Conclusion}

Rabies case surveillance using only pan-lyssavirus reactive antisera in dFAT does not provide sufficient information to fully understand the epidemiology of rabies in a region where multiple lyssaviruses are circulating. Whilst virus 
characterisation by genetic sequencing provides definitive information with regard to virus type, mAb typing is a useful screening tool that can be done quickly and at comparatively lower cost. This study has illustrated the value of $\mathrm{mAb}$ typing to identify species of the Lyssavirus genus and has contributed to an understanding of the epidemiology of rabies and rabies-related viruses in South Africa; however, evaluation of detailed relationships amongst isolates requires the use of more sophisticated molecular techniques that are not impacted to the same degree by sample quality. Routine lyssavirus differentiation using mAbs should be continued in synergy with nucleotide sequencing in this region. Such studies can inform the design of rabies control strategies, may assist in the identification of reservoir species (as in the case of MOKV), and may also lead to the identification of new lyssavirus species (Kuzmin et al. 2010).

\section{Acknowledgements}

The authors would like to thank Drs Livio Heath and Susan Nadin-Davis for critically reviewing the manuscript and also Ms Debra Mohale and Dr Wonderful Shumba for their technical support. This work was partly funded by the Rabies Diagnostic Project, Onderstepoort Veterinary Research Institute (OVI 15/4/P001) and the European Virus Archive (EVA) $(04 / 17 / C 215)$.

\section{Competing interests}

The authors declare that they have no financial or personal relationship(s) which may have inappropriately influenced them in writing this article.

\section{Authors' contributions}

E.N. (Agricultural Research Council-Onderstepoort Veterinary Institute) and C.S. (Agricultural Research CouncilOnderstepoort Veterinary Institute) were responsible for the design of the study and writing of the manuscript. C.F-G. (Canadian Food Inspection Agency) and A.W. (Canadian Food Inspection Agency) were involved in the writing of the manuscript.

\section{References}

Agricultural Research Council-Onderstepoort Veterinary Institute (ARC-OVI), 2007, 'Monoclonal antibody typing: Report', Claude Sabeta, Pretoria.

Badrane, H., Bahloul, C., Perrin, P. \& Tordo, N., 2001, 'Evidence of two Lyssavirus phylogroups with distinct pathogenicity', Journal of Virology 75, 3268-3276. http://dx.doi.org/10.1128/JVI.75.7.3268-3276.2001

Bingham, J., Javangwe, A., Sabeta, C.T., Wandeler, A.I. \& Nel, L.H., 2001, 'Report of isolations of unusual lyssaviruses (rabies and Mokola virus) identified retrospectively in Zimbabwe', Journal of the South African Veterinary Association 72, 92-94. http://dx.doi.org/10.4102/jsava.v72i2.624

Dean, D.J., Abelseth, M.K. \& Atanasiu, P., 1996, 'The fluorescent antibody test', in F.X. Meslin, M.M. Kaplan \& H. Koprowski (eds.), Laboratory Techniques in Rabies, 4th edn., pp. 88-95, World Health Organization, Geneva.

Dietzgen, R.G., Calisher, C.H., Kurath, G., Kuzmin, I.V., Rodriguez, L.L., Stone, D.M. et al., 2011, 'Rhabdoviridae', in A.M.Q. King, M.J. Adams, E.B. Carstens \& E.J. Lefkowitz (eds.), Virus Taxonomy: Ninth report of the International Committee on Taxonomy of Viruses, pp. 654-681, Elsevier, Oxford.

Favoretto, S.R., Carrieri, M.L., Cunha, E.M.S., Aguiar, E.A.C., Silva, L.H.Q., Sodrè, M.M. et al., 2002, 'Antigenic typing of Brazilian rabies virus samples isolated from animals and humans, 1989-2000', Revista do Instituto de Medicina Tropical de São Paulo 44 (2), 91-95. http://dx.doi.org/10.1590/\$0036-46652002000200007

Favoretto, S.R., De Mattos, C.C., De Morais, N.B., Carrieri, M.L., Rolim, B.N., Silva, L.M et al., 2006, 'Rabies virus maintained by dogs in humans and terrestrial wildlife,
Cearả state, Brazil', Emerging Infectious Diseases 12 (12), 1978-1981. http:// dx.doi.org/10.3201/eid1212.060429

Fehlner-Gardiner, C., Nadin-Davis, S., Armstrong, J., Muldoon, F., Bachmann, P. \& Wandeler, A., 2008, 'ERA vaccine-derived cases of rabies in wildlife and domestic animals in Ontario, Canada, 1989-2004', Journal of Wildlife Diseases 44, 71-85. http://dx.doi.org/10.7589/0090-3558-44.1.71

Foggin, C.M., 1988, 'Rabies and rabies-related viruses in Zimbabwe: Historical, virological and ecological aspects', PhD thesis, University of Zimbabwe, Harare, Zimbabwe.

Freuling, M.C., Beer, M., Conraths, F.J., Finke, S., Hoffmann, B., Keller, B. et al., 2011, 'Novel lyssavirus in Natterer's bat, Germany', Emerging Infectious Diseases 17(8), 1519-1522.

Gould, A.R., Hyatt, A.D., Lunt, R., Kattenbelt, J.A., Hengstberger, S. \& Blacksell, S.D., 1998, 'Characterization of a novel lyssavirus isolated from pteropid bats in Australia', Virus Research 54, 165-187. http://dx.doi.org/10.1016/S01681702(98)00025-2

Hills, D.M. \& Bull, J.J., 1993, 'An empirical test of bootstrapping as a method for assessing confidence in phylogenetic analysis', Systematic Biology 42, 182-192. http://dx.doi.org/10.1093/sysbio/42.2.182

International Committee on Taxonomy of Viruses, n.d., ICTV official taxonomy: Updates since the 8th report. Vertebrate International Committee on Taxonomy of Viruses, 2014 release, viewed 25 April 2014, from http://ictvonline.org/ virusTaxonomy.asp_

Johnson, N., Letshwenyo, M., Baipoledi, E.K., Thobokwe, G. \& Fooks, A.R., 2004 'Molecular epidemiology of rabies in Botswana: A comparison between antibody typing and nucleotide sequence phylogeny', Veterinary Microbiology 101, 31-38. http://dx.doi.org/10.1016/j.vetmic.2004.03.007

King, A.A., Meredith, C.D. \& Thomson, G.R., 1993, 'Canid and viverrid rabies viruses in South Africa', Onderstepoort Journal of Veterinary Research 60, 295-299.

Kumar, S., Tamura, K. \& Nei, M., 2004, 'MEGA3: Integrated software for molecular evolutionary genetics analysis and sequence alignment', Briefings in Bioinformatics 5, 150-163. http://dx.doi.org/10.1093/bib/5.2.150

Kuzmin, I.V., Mayer, A.E., Niezgoda, M., Markotter, W., Agwanda, B., Breiman, R.F. et al., 2010, 'Shimoni bat virus, a new representative of the Lyssavirus genus', Virus Research 149(2), 197-210. http://dx.doi.org/10.1016/j.virusres.2010.01.018

Markotter, W., Kuzmin, I., Rupprecht, C.E., Randles, J., Sabeta, C.T., Wandeler, A.I. et al., 2006, 'Isolation of Lagos bat virus from water mongoose', Emerging Infectious Diseases 12, 1913-1918. http://dx.doi.org/10.3201/eid1212.060514

Marston, D.A., Horton, D.L., Ngeleja, C., Hampson, K., McElhinney, L.M., Banyard, A.C. et al., 2012, 'Ikoma lyssavirus, identification of a highly divergent novel Iyssavirus in an African civet (Civettictis civetta)', Emerging Infectious Diseases 18 (4), 664-667. http://dx.doi.org/10.3201/eid1804.111553

Nadin-Davis, S. \& Bingham, J., 2004, 'Europe as a source of rabies for the rest of the world', in A.A. King, A.R. Fooks, M. Aubert \& A.I. Wandeler (eds.), Historical Perspective of Rabies in Europe and the Mediterranean Basin, pp. 259-280, World Perspective of Rabies in Europe and the
Organisation for Animal Health, Paris.

Nadin-Davis, S.A., Sheen, M., Abdel-Malik, M., Elmgren, L. Armstrong, J. \& Wandeler, A.I., 2000, 'A panel of monoclonal antibodies targeting the rabies virus phosphoprotein identifies a highly variable epitope of value for sensitive strain phosphoprotein identifies a highly variable epitope of value for
discrimination', Journal of Clinical Microbiology 38, 1397-1403.

Nadin-Davis, S.A., Huang, W., Armstrong, J., Casey, G.A., Bahloul, C., Tordo, N. et al., 2001, 'Antigenic and genetic divergence of rabies viruses from bat species et al., 2001, 'Antigenic and genetic divergence of rabies viruses from bat species
indigenous to Canada', Virus Research 74, 139-156. http://dx.doi.org/10.1016/ indigenous to Canada',
S0168-1702(00)00259-8

Nadin-Davis, S.A., Fehlner-Gardiner, C. Sheen, M. \& Wandeler, A.I., 2010 'Characterization of a panel of anti-phosphoprotein monoclonal antibodies generated against the raccoon strain of rabies virus', Virus Research 152,126-136. generated against the raccoon strain of rabies virus',
$\mathrm{http}: / / \mathrm{dx}$.doi.org/10.1016/j.virusres.2010.06.014

Nel, L.H., Sabeta, C.T., Von Teichman, B., Jaftha, J.B., Rupprecht, C.E. \& Bingham, J. 2005, 'Mongoose rabies in southern Africa: A re-evaluation based on molecular epidemiology', Virus Research 109, 165-173. http://dx.doi.org/10.1016/ epidemiology', Virus
j.virusres.2004.12.003

Ngoepe, C.E., Sabeta, C.T. \& Nel, L.H., 2009, 'The spread of canine rabies into Free State province of South Africa: A molecular epidemiological characterization', Virus Research 142, 175-180. http://dx.doi.org/10.1016/j.virusres.2009.02.012

Rupprecht, C.E., Dietzschold, B., Wunner, W.H. \& Koprowski, H., 1991, 'Antigenic relationships of lyssaviruses', in G.M. Baer (ed.), The Natural History of Rabies, 2nd edn., pp. 69-10, CRC Press, Boca Raton.

Sabeta, C.T., Mansfield, K.L., McElhinney, L.M., Fooks, A.R. \& Nel, L.H., 2007a, 'Molecular epidemiology of rabies in bat-eared foxes (Otocyon megalotis) in South Africa', Virus Research 129, 1-10. http://dx.doi.org/10.1016/j.virusres.2007.04.024

Sabeta, C.T., Markotter, W., Mohale, D.K., Shumba, W., Wandeler, A.I. \& Nel, L.H., 2007b, 'Mokola virus in domestic mammals, South Africa', Emerging Infectious Diseases 13, 1371-1373. http://dx.doi.org/10.3201/eid1309.070466

Sabeta, C.T., Shumba, W., Mohale, D.K., Miyen, J.M., Wandeler, A.I. \& Nel, L.H., 2008 'Mongoose rabies in the African civet in Zimbabwe', Veterinary Record 163, 580. http://dx.doi.org/10.1136/vr.163.19.580

Sacramento, D., Bourhy, H. \& Tordo, N., 1991, 'PCR techniques as an alternative method for diagnosis and molecular epidemiology of rabies virus', Molecular and Cellular Probes 6, 229-240. http://dx.doi.org/10.1016/0890-8508(91)90045-L

Saitou, N. \& Nei, M., 1987, 'The neighbour-joining method: A new method for reconstructing phylogenetic trees', Molecular Biology and Evolution 4, 406-425.

Schneider, L.G., Cox, J.H., Muller, W.W. \& Hohnsbeen, K.P., 1988, 'Current oral rabies 
vaccination in Europe: An interim balance', Reviews of Infectious Diseases 10 S654-S659. http://dx.doi.org/10.1093/clinids/10.Supplement_4.S654

Smith, J.S., 2002, 'Molecular epidemiology', in A.C. Jackson \& H.W. Wunner (eds.) Rabies, pp. 79-111, Academic Press, San Diego, United States of America.

Smith, J.S. \&. King, A.A., 1996, 'Monoclonal antibodies for the identification of rabies and non-rabies lyssaviruses', in F.X Meslin, M.M. Kaplan \& H. Koprowsk (eds.), Laboratory Techniques in Rabies, 4th edn., pp. 145-156, World Health Organization, Geneva.

Snyman, P.S., 1940, 'The study and control of vectors of rabies in South Africa', Onderstepoort Journal of Veterinary Research 66, 296-307.

Swanepoel, R., 2004, 'Rabies', in J.A.W. Coetzer \& R.C. Tustin (eds.), Infectious Diseases of Livestock, 2nd edn., vol. 2, pp. 1123-1182, Oxford University Press, Cape Town

Tremlett, J.G., Wibberley, G. \& King, A.A., 1994, 'Rabies virus typing-preliminary survey in Botswana', Tropical Animal Health and Production 26, 157-160. http:// dx.doi.org/10.1007/BF02241072
Van Zyl, N., Markotter, W. \& Nel, L.H., 2010, 'Evolutionary history of African mongoose rabies', Virus Research 150, 93-102. http://dx.doi.org/10.1016/ j.virusres.2010.02.018

Von Teichman, B.F., De Koker, W.C., Bosch, S.J., Bishop, G.C., Meredith, C.D. \& Bingham, J., 1998, 'Mokola virus infection: Description of recent South African cases and a review of the virus epidemiology', Journal of the South African Veterinary Association 69(4), 169-171. http://dx doi.org/10.4102/jsava.v69i4.847

Von Teichman, B.F., Thomson, G.R., Meredith, C.D. \& Nel, L.H., 1995, 'Molecular epidemiology of rabies virus in South Africa: Evidence of two distinct virus groups', Journal of General Virology 76, 73-82. http://dx.doi.org/10.1099/00221317-76-1-73

Zulu, G.C., Sabeta, C.T. \& Nel, L.H., 2009, 'Molecular epidemiology of rabies: Focus on domestic dogs (Canis familiaris) and black-backed jackals (Canis mesomelas) from northern South Africa', Virus Research 140, 71-78. http://dx doi.org/10.1016/ j.virusres.2008.11.004

Zulu, C.G., 2007, 'Molecular epidemiology of rabies in northern South Africa and southern Zimbabwe demonstrates an epidemiological complexity that involves domestic dogs and jackals (Canis mesomelas)', MSc thesis, University of Pretoria. 